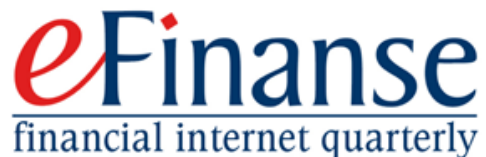

\section{PAPER PROFITS FROM VALUE, SIZE AND MOMENTUM: EVIDENCE FROM THE POLISH MARKET}

\author{
Adam Zaremba ${ }^{1}$, Przemysław Konieczka ${ }^{2}$
}

Abstract In this paper we investigate sources and characteristics of value, size and momentum profits on the Polish stock market. The research aims to broaden the academic knowledge in a few ways. First, we deliver fresh out-of-sample evidence on value, momentum, and size premiums. Second, we analyze the interdependences among the factors. Third, we investigate whether the factor premiums are present after accounting for liquidity constraints. Fourth, we check whether the factor premiums are robust to transaction costs. Our research is based on all the stocks listed on the WSE in years 2001-2013. We find, that the value, momentum, and size premiums are to some extent present on the Polish market. Furthermore, they strengthen each other, but they disappear after accounting for transaction costs and liquidity.

JEL Classification: G11, G12, G14

Keywords: value premium, size premium, momentum effect, cross-section of stock returns, liquidity, transaction costs, Warsaw Stock Exchange, WSE, Polish stock market 


\section{INTRODUCTION}

Since Fama and French invented their three-factor model (Fama \& French, 1992; 1993), the research on cross-sectional variation in stock returns has proliferated. One of the most widely recognized offsprings was the Carhart four-factor model (Carhart, 1997), which incorporated value, size and momentum effects. Carhart's computations were frequently repeated and extended to different markets. The aim of our paper is to further investigate Carhart's value, momentum and size effects, their sources and characteristics.

Carhart's model refers to three effects observed in empirical data in stock markets. First, the value effect is the tendency of value stocks (stocks with low prices relative to their fundamentals) to outperform growth stocks (stocks with high prices relative to their fundamentals). The value effect is usually measured based on the ratio of book value of equity divided by market value of equity (B/M). Formal statistical evidence of the value effect was presented by Stattman (1980) and Rosenberg (1985). They used the book to market ratio as a value indicator. Davis et al. (1994) confirmed the value effect in US stock markets. Chan et al. (1991) and Capaul et al. (1993) confirmed the value effect outside the US markets. The value effect was observed in stock returns by Chan et al. (1991), Fama and French (1998; 2012), Rouwenhorst (1999), Chui et al. (2010), Asness et al. (2013), Zaremba (2015a; 2015b), and Zaremba and Konieczka (2015). Lischewski and Voronkova (2012), Kowerski (2006), Czapkiewicz and Skalna (2010), and Zaremba (2014c) confirmed the value effect on the Polish equity market.

Second, the size effect was initially documented by Banz (1981). Banz found that the smallest quintile of firms produces an annual return that is 5 per cent higher than the return on other firms. In other words, he showed that stocks with lower capitalization (small stocks) tend to have higher average returns. Banz carried out the research on return premium on small stocks during the 1936-1975 period for the stocks quoted on the NYSE. In the literature the companies' sizes are usually measured with their stock market capitalizations. Reinganum (1981) and Cook and Roseff (1982) confirmed the evidence of the size effect by using a broader sample and decile portfolios. The size effect was later confirmed by Blume and Stambaugh (1983) and Brown et al. (1983). In particular, the size effect was detected in
US markets and several international markets by a variety of researchers[Herrera \& Lockwood (1994), Heston et al. (1999), Rouwenhorst (1999), Horowitz et al. (2000), Fama \& French (2008), Michou et al. (2010), Zaremba (2015a, 2015b), and Zaremba \& Konieczka (2015)].

Lischewski and Voronkova (2012) and Zaremba (2014) estimated the impact of size effect on returns in the Polish equity market. They found that the size factor plays a significant role in explaining returns on Polish stocks.

Finally, the momentum effect is based on the observation by Jagadeesh and Titman (1993) that stocks with high past performance (winners) outperform stocks with low past performance (losers) in the short-term horizon. The momentum strategy relies on buying the winner portfolio and shorting the loser portfolio. The initial study of this pattern in stock returns was the work of DeBondt and Thaler (1985). They found strong evidence that recent well performing stocks become poor performers over 3-year and 5-year holdings. Jagadeesh and Titman (1993; 2001) performed an analysis similar to DeBondt and Thaler (1985) but with focus on a short-term investment horizon. The evidence of the momentum factor in returns of stocks in the international markets was proven by Asness (1994), Fama and French (1998; 2011), Rouwenhorst (1999), Liew and Vassalou (2000), Grinblatt and Moskowitz (2004), Chui, Wei, and Titman (2010), and Asness et al. (2013), Zaremba (2014; 2015a; 2015b), and Zaremba and Konieczka (2015).

This paper aims to broaden academic knowledge in a few ways. First, we deliver fresh evidence on value, momentum, and size premiums from the biggest emerging market in Eastern Europe, which has not been analyzed in a comprehensive way so far Poland. Second, we analyze the interdependence among the return factors and check whether they diminish or amplify each other. Third, we investigate if Carhart's factor premiums are present after accounting for liquidity. Fourth, we check whether the factor premiums are robust to transaction costs. Our basic hypotheses are that the value, momentum and size premiums are present in the Polish market and additionally can be amplified by combining them with each other; however they only compensate investors for transaction costs and illiquidity. 
The paper is opened with an introduction followed by sections. First, we present the data sources and research methods employed. Then, we discuss our research results. The last section concludes the paper. Our research is based on all the stocks listed on the WSE in the years 2000-2013. The last part of the paper includes concluding remarks and indications for further research.

\section{RESEARCH MethodS and Data Sources}

We investigate the issue of returns on momentum, value, and size factors on the Polish market based on all stocks listed on the Warsaw Stock Exchange between 09/25/2001 and 09/25/2013. The data comes from Bloomberg. We use both listed and delisted stocks in order to avoid the survivorship bias. First, we analyze the factor returns on the Polish market. We sort all the stocks at a given time on metrics related to value, size, and momentum. These measures are defined as follows:

1) value metric $(V)$ - the book value to market value ratio $(B / M)$ at the time of portfolio formation,

2) size metric $(S)$ - the total market capitalization of a company at the time of portfolio formation,

3) momentum metric $(M)$ - the 12-month realized rate of return in the year preceding the portfolio formation.

We use only these stocks that had all four computable characteristics in a given year. The number of stocks in the sample grew along with the development of the Polish capital market from 31 in the beginning of the research period to 413 in the end. Based on the $\mathrm{V}, \mathrm{S}$ and $\mathrm{M}$ characteristics, we form three separate portfolios, for each metric including $30 \%$ of stocks with the lowest metric, $30 \%$ of stocks with the highest metric and the remaining $40 \%$ of the mid-stocks. We use three different weighting schemes. The first type of portfolio relies on the equal-weighting approach, which means that each stock participates equally in the portfolio at the time of formation. The second method is capitalization-weighting, which means that the weight of each stock is proportional to the total market capitalization of the company at the time of portfolio formation. The last scheme is liquidity-weighting. As a proxy for liquidity we use the turnover, which is the average of daily trading volumes in the month preceding the portfolio formation multiplied by the last closing price. The reason we use liquidity-weighting is that many stocks in the emerging markets tend to be significantly illiquid. As a result, the regular reconstruction and rebalancing of equal or capitalization-weighted portfolios may be completely unrealistic. The liquidity-weighted portfolios are the easiest to reconstruct and rebalance within a market segment. In other words, by using liquidity-weighted portfolios we avoid an illiquidity bias which may arise due to some inherent illiquidity premium linked to illiquid companies. The participation of such companies in both equal-weighted and capitalization-weighted portfolios may be artificially overweighted to an unrealistic level, something which cannot be achieved by a real investor. Thus, liquidity-weighting is far better aligned with a true investor's point of view, as it avoids the impact of "paper" profits from illiquid assets.

It is also important to point out that the liquidityweighting approach does not deal with the issue of the illiquidity premium entirely, as some securities with similar characteristics (like high $\mathrm{B} / \mathrm{M}$ ) may be illiquid as a group and thus bear some illiquidity premium. Nonetheless, this research assumes the point of view of an individual investor with a medium-size portfolio, for whom such group illiquidity does not pose a problem. A detailed analysis taking advantage of a more sophisticated price impact function to account for illiquidity is beyond the scope of this paper.

Along with the factor portfolios, we also calculate returns on the market portfolio, by which we mean the portfolio of all the stocks in the sample. For better comparison, we compute the market portfolios each time using the same methodology as for the factor portfolios. In other words, we compute three different market portfolios: equal, capitalization and liquidity-weighted. All factor and market portfolios are reconstructed and rebalanced once a year on the 25th of September. The date was chosen intentionally in order to avoid look-ahead bias. We intentionally choose annual rebalancing and timeseries (contrary to monthly rebalancing usually used in similar studies) to better align to the point of view of an individual investor, who is not always able to rebalance his or her portfolio on a monthly basis. In addition, the more frequent rebalancing could unnecessarily increase the transaction costs.

Next, we build long/short (L/S) portfolios mimicking the behavior of certain factors. The construction 
of $L / S$ portfolios is based on existing theoretical and empirical evidence in the field, so as to make them positively exposed to factor-related premiums. In other words, the portfolios are always long the $30 \%$ of stocks that yield the highest risk-adjusted returns, short in the $30 \%$ of stocks that yield the lowest risk-adjusted returns and $100 \%$ long in the risk-free assets. As a result, we create three distinct portfolios:

1) value market neutral long/short mimicking portfolio ("value $\mathrm{L} / \mathrm{S}$ "), which is $100 \%$ long the $30 \%$ of the highest $\mathrm{B} / \mathrm{M}$ stocks, $100 \%$ short the $30 \%$ of the lowest $\mathrm{B} / \mathrm{M}$ stocks and $100 \%$ long the risk free asset,

2) size market neutral long/short mimicking portfolio ("size L/S"), which is $100 \%$ long the $30 \%$ of the smallest companies, $100 \%$ short the $30 \%$ of the biggest companies and $100 \%$ long the risk free asset,

3) momentum market neutral long/short mimicking portfolio ("momentum L/S"), which is $100 \%$ long in the $30 \%$ of the highest momentum stocks, $100 \%$ short in the $30 \%$ of the lowest momentum stocks and $100 \%$ long the risk free asset.

Again, as in the previous case, the stocks in the portfolios are weighed according to three different schemes: equal-based, capitalization-based and liquidity-based.

Finally, the performance of long/short portfolios is tested against CAPM [described for example in: Cambell et al. (1997)]. Here, we base our computations on log-returns. The long/short portfolios' excess returns were regressed on the market portfolio's excess returns, accordingly to the CAPM equation

$$
R_{p t}-R_{f t}=\alpha_{i}+\beta_{i}\left(R_{m t}-R_{f t}\right)+\varepsilon_{p t}
$$

where:

$R, R$ and $R$ are annual long/short portfolio, market portfolio and risk-free returns, and $\alpha_{i}$ and $\beta_{i}$ are regression parameters.

We use 1-year Warsaw Interbank Offered Rate (WIBOR) bids to represent the risk-free rate. The ai intercept measures the average annual abnormal return (so called Jensen's alpha). Our zero hypothesis is that the alpha intercept is not statistically different from zero, and the alternative hypothesis states that it is actually different from zero. We find the equation parameters using OLS and test them in a parametric way.
Having tested the performance of portfolios from single sorts, we analyze the interactions between the individual effects. First, for presentational purposes, we compute time-series correlation matrices of $\mathrm{L} / \mathrm{S}$ portfolios. Next, we provide more formal statistical inferences. At this stage, all computations are based on equal-weighted portfolios. We divide the stocks into separate double-sorted groups based on combinations of their fundamental characteristics described above: $\mathrm{V}, \mathrm{S}$ and $\mathrm{M}$. This is done as follows. Firstly, we assigned each stock to one of the subsamples, based on the metrics above: low $30 \%$, mid $40 \%$ or high $30 \%$. In other words, we segregated all the stocks into low, medium or high $\mathrm{V}$, low, medium or high $\mathrm{S}$, and low, medium or high $\mathrm{M}$. Secondly, we intersect both independent divisions and thus create nine portfolios for each pair of the above fundamental factors. For instance, in the case of the $\mathrm{V}+\mathrm{S}$ pair, we created the low $\mathrm{V}$ and low $S$ portfolio which consisted of stocks that belonged simultaneously to the low $\mathrm{V}$ subgroup and low $\mathrm{S}$ subgroup; the low $\mathrm{V}$ and medium $\mathrm{S}$ portfolio which consisted of stocks that belonged simultaneously to the low $V$ subgroup and medium $S$ subgroup; and so on with 7 other $V+S$ portfolios. We did the same for other pairs $(\mathrm{V}+\mathrm{M}, \mathrm{M}+\mathrm{S})$, finally arriving at 27 portfolios.

Next, we construct double-sorted long/short portfolios for each of the pairs. The premises of certain long/short portfolios are based on existing theoretical and empirical evidence. Thus, we create the following equal-weighted portfolios:

1) $100 \%$ long high $V$ and high $M, 100 \%$ short low $V$ and low $\mathrm{M}, 100 \%$ long the risk-free asset,

2) $100 \%$ long high $V$ and low $S, 100 \%$ short low $V$ and high S, 100\% long the risk-free asset,

3) $100 \%$ long high $M$ and low $S, 100 \%$ short low $M$ and high S, 100\% long the risk-free asset.

For example, the first long/short portfolio is $100 \%$ long in stocks which belong at the same time to the high value and high momentum subgroups, and $100 \%$ short in stocks which belong at the same time to the low value and low momentum subgroups. Finally, we test the described portfolios against CAPM using procedures identical to those described above.

In the last phase of our research, we take into account the transaction costs differences among 
various portfolios. We use a simple proportional cost model, so the cost function could be described as (Korajczyk \& Sadka, 2004):

$$
f(p)=k \times p
$$

where:

$p$ is the stock price at the time of portfolio formation and $k$ is the constant cost component. As the proxy for the $k$ we use half of the quoted spread, which is defined as:

$$
\mathrm{k}_{\mathrm{j}, \mathrm{t}}=\frac{1}{2} \times \mathrm{k}_{\mathrm{j}, \mathrm{t}}^{\mathrm{Q}}
$$

where:

$$
\mathrm{k}_{\mathrm{j}, \mathrm{t}}^{\mathrm{Q}}=\frac{\mathrm{P}_{\mathrm{ask}, \mathrm{j}, \mathrm{t}}-\mathrm{P}_{\text {bid, }, \mathrm{t}, \mathrm{t}}}{\mathrm{P}_{\text {mid }, \mathrm{j}, \mathrm{t}}}
$$

and Pask,j,t, Pbid,j,t and Pmid,j,t are offer, bid and mid prices of stock $j$ at time $t$. Using the $\mathrm{k}_{\mathrm{j}, \mathrm{o}}^{\mathrm{Q}}$ measure, we compute the full sample time-series averages of cross-sectional averaged spreads within the specific market and factor portfolios. We use all three distinct weighting schemes.

Next, we compute simplified post-cost returns by employing following formula:

$$
R_{p o s t-\cos t}=R_{p r e-\cos t}-\left(k_{j, t_{0}}+k_{j, t 1}\right)
$$

where:

$k_{j, t_{0}}$ and $k_{j, t 1}$ are the constant cost components (halves of the quoted spreads) at the beginning and at the end of the measurement period. In other words, we take a simplified approach by assuming an equal $100 \%$ turnover rate in all portfolios. Finally, using the post-cost returns and log-returns, we repeat all the computations and statistical interfering in the same way as for the raw pre-cost returns. It is important to emphasize that all the portfolios' returns, including market portfolios' return, are computed based on post-cost returns. We do so in order to avoid the problem of comparing apples and oranges during the analysis.

\section{Results AND Discussion}

Table 1 presents pre-cost returns of factor portfolios. The computation of equal-weighted factor portfolios indicates that some form of value, size and momentum effect is present on the Polish market. In the case of value, the top $30 \%$ portfolio delivered returns 7.4 p.p. higher than the low $30 \%$ portfolio and 1.5 p.p. better than the market portfolio. Interestingly, the high $\mathrm{B} / \mathrm{M}$ portfolio was actually slightly less risky than the market and low $B / M$ portfolios. These differences were even bigger in the case of the size effect. Small companies yielded returns 13 p.p. better than market portfolios and 5.1 p.p. better than the market portfolio. However, the bigger profits came not without a higher risk measured with either standard deviation or beta. Finally, at first glance the momentum effect seems to be the strongest among the three analyzed portfolios. The difference in returns between high and low momentum stocks reached 16 p.p., although it appears that the high momentum stocks were slightly more risky. Unfortunately, a significant part of profits disappear when we use the capitalization-based rather than equal-based weighting scheme. The difference between top and bottom portfolios shrank to 4.6 p.p. in case of the value factor and 10.1 p.p. in case of the size factor, although it was still considerably large. Curiously, the momentum effect actually disappeared entirely and the low momentum stocks yielded results 5.5 p.p. more than high momentum stocks. What is more, all three factor premiums turned out to be not robust to liquidity-weighting. The premiums were reversed for the value and size factors. In the case of momentum, the top momentum portfolios still delivered higher returns (adjusted and not adjusted for risk) than low momentum portfolios, but both portfolios were at any rate worse performers than the market portfolio. These results were generally confirmed by the analysis of the long/short factor mimicking portfolios, although the outcome of such analysis lacked strong statistical significance (Table 2). This fact may be due to the relatively short timeseries on the young Polish market. All the three L/S portfolios yielded positive returns. However, after adjusting the weights for individual liquidity of stocks, all returns and risk-adjusted returns for the three factors became negative. To summarize, it seems that on the Polish market factor premiums are not immune to the question of stock liquidity. In fact, after adjusting for liquidity, the factor premiums seem nonexistent.

Table 3 exhibits time-series correlations among the L/S factor mimicking portfolios. Strikingly, the correlations are highly dependent on the weighting scheme. For instance, the correlation between value and size $\mathrm{L} / \mathrm{S}$ equal weighed portfolios was $-0,41$, while after adjusting portfolio weights for capitalization the correlation turned positive and reached the level of 0,56 . Table 4 depicts some 
interactions of equal-weighted factor portfolios. Interestingly, the value and size interdependencies seem to somehow contradict previous empirical evidence from developed markets. The value premium was negative in the case of small stocks, and relatively higher in case of medium and large stocks. On the other hand, the value and momentum factors appear to clearly amplify each other. The top value and top momentum portfolio yielded an annual return of $30.9 \%$ and the bottom value and bottom momentum portfolio's return was negative and equal to $-2.3 \%$. In other words, the difference in returns was as high as 33.3 p.p. per year. However, it is important to note that the better performing portfolio was also more risky, no matter whether risk is measured with standard deviation or with beta. Similar synergy effects could be seen in case of size and momentum factors. The small high momentum stocks delivered a $39.1 \%$ annual rate of return, while the big low momentum stocks only managed $5.8 \%$, the difference thus reaching 32.8 p.p. Nonetheless, the volatility of the best performing portfolio was also impressive, as the standard deviation was equal to $68.9 \%$. This extraordinary volatility is probably one of the factors contributing to the fact that the two-factor market neutral portfolios deliver impressive, but statistically insignificant abnormal rates of return (Table 5.) The only exception was the volume-momentum portfolio, which yielded an annual rate of return amounting to $39,2 \%$ and delivered a 31,11\% annual CAPM alpha.

In order to verify whether the factor premiums are robust to trading costs, we initially computed the average spreads in various portfolios, which allowed for a few interesting observations. The results are presented in Table 6. First, as could be expected, the average spreads for the equal-weighted (EW) portfolios were significantly higher than for the capitalization-weighted (CW) and liquidity-weighted (LW) portfolios. In the case of the entire market portfolio, the EW was equal to $2,71 \%$, and in the case of LW it was more than 5 times less at 0,52\%. This situation is due to very large spreads among the smallest stocks. Even in the liquidity-weighted smallcap portfolio the spreads were on average as high as $2,56 \%$. Finally, in the case of momentum portfolios, the spreads are generally wider for low momentum portfolios than for high momentum portfolios. To summarize, the consequences of variations in spreads among different group of companies may cause the small-cap stocks to be diminished, while the value and momentum stocks are even increased. Table 7 depicts the post-cost returns of various factor portfolios. From analyzing the table, we can draw a few interesting conclusions. First, the transaction costs diminish the size premium. In the case of liquidity-weighting they turned out to be significantly negative. In other words, it appears that transaction costs are so large that they cannot be compensated even by the size premium. On the other hand, the returns to momentum and value - in the portfolios they were already present - do not obliterate, but sometimes even increase. Nonetheless, it is worth noting that after accounting for both transaction costs and liquidity, literally none of the analyzed factors seem to work. These observations are generally confirmed by an analysis of returns from the long/short factor mimicking portfolios . Except for the CW value portfolios, the average returns for all portfolios are vividly lower. Additionally, all the CAPM alphas - with the exception of equalweighted momentum portfolio - become negative or close to zero. To conclude, the transaction costs generally have negative influence on returns of portfolios from sorts on value, size, and momentum metrics. Nonetheless, when combined with the impact of liquidity, they significantly impede the factor performance.

\section{Conclusions}

In this paper we conduct research on the robustness and interdependencies of Carhart's model factors on Polish markets. The analysis allowed us to draw a few interesting conclusions and answer the initial questions stated in the beginning of the paper. First, we deliver fresh evidence on the value, size and momentum premiums from the emerging Polish market, which have not been comprehensively analyzed so far. We observe visible positive value, size and momentum premiums, which however lack statistical significance. Second, we find some interesting interactions between pairs of these effects. Value, size, and momentum effects seem to amplify each other, triggering superior results for combined value/momentum and size/momentum portfolios. On the other hand, the results for the value/size combination appear rather equivocal and contradict previous empirical evidence from developed markets. Third, we check whether the factor premiums are robust to liquidity. The answer 
seems to be negative, as after adjusting the factor portfolio weights for liquidity, the value, momentum and size premiums completely evaporate. Fourth, we investigate the impact of transaction costs on Carhart's factor premiums. The market spread variation has the biggest negative influence on the small-cap premium. Additionally, it has not such a significant impact on momentum effect and value effect. Moreover, when we focus on the relatively costly market neutral factor mimicking portfolios, the factor alphas become close to zero or negative. Finally, when we account for both the liquidity and transaction costs, the factor premiums cease to exist. Summarizing, our observations are rather pessimistic from an investor's point of view. They indicate that even though factor premiums are present in the Polish market, they do not bring any profit, as they simply compensate for the higher illiquidity and transaction costs.

Further research on issues discussed in this paper could be pursued in several directions. First, it might be useful to enlarge the research sample. Since it may be difficult to make the time-series longer (the "emerging" nature of the emerging markets makes them rather young), it would be interesting to verify whether similar phenomena can be observed in other emerging markets. Second, the factor interactions should be analyzed with different weighting schemes of the analyzed portfolios. Third, one of the drawbacks of our computations was that we used a relatively simple cost function and rather strong assumptions on portfolio turnover. On the one hand, it might be interesting to allow for variable portfolio turnover, but on the other, the results of research may be improved by using more sophisticated cost functions accounting for market impact, as for example in Glosten-Harris (1988), Breen-Hodrick-Korajczyk (2002) or Almgreen-ThunHauptmann-Li (2005). Finally, the most important issue which should be further investigated is probably the impact of liquidity on factor premiums. The analysis should concentrate on the question of whether liquidity is the missing link that could entirely or at least partially explain the value, size and momentum premiums in emerging markets.

\section{REFERENCES}

Asness, C.S., Moskowitz, T.J., Pedersen, L.H. (2013). Value and Momentum Everywhere. The Journal of Finance, 68(3), 929-985.

Asness, C.S. (1994). Variables that Explain Stock Returns. Ph.D. Dissertation, University of Chicago.

Banz, R.W. (1981). The Relation between Return and Market Value of Common Stocks. Journal of Financial Economics, 9, 3-18.

Blume, M.E., Stambaugh, R.F. (1983). Biases in Computed Returns: An Application to the Size Effect. Journal of Financial Economics, 12(3), 387-404.

Brown, P., Keim, D.B., Kleidon, A.W., Marsh, T.A. (1983). Stock Return Seasonalities and the Tax-loss Selling Hypothesis: Analysis of the Arguments and Australian Evidence. Journal of Financial Economics, 12, 105-128.

Cambell, J.Y., Lo, A.W., MacKinlay, A.C. (1997). The Econometrics of Financial Markets. Princeton, New Jersey: Princeton University Press.

Carhart, M.M. (1997). On Persistence in Mutual Fund Performance. The Journal of Finance, 52(1), 57-82.

Chan, L.K.C., Hamao, Y., Lakonishok, J. (1991). Fundamentals and Stock Returns in Japan.

The Journal of Finance, 46(5), 1739-1764.

Chui, A.C.W., Titman, S., Wei, K.C.J. (2010). Individualism and Momentum around the World. The Journal of Finance, 65(1), 361-392.

Cook, T.J., Roseff, M. (1982). Size Dividend Yield and Co-Skewness Effects on Stock Returns: Some Empirical Tests. lowa City: University of lowa, Working Paper Series 18, 82-20.

Czapkiewicz, A., Skalna, I. (2010). The CAPM and Fama-French Models in Poland. Przeglqd Statystyczny, 57(4), 128-141.

Davis, L.J. (1994). The Cross-section of Realized Stock Returns: The pre-COMPUSTAT Evidence.

The Journal of Finance, 49(5), 1579-1593.

De Bondt, W., Thaler, R. (1985). Does the Stock Market Overreact? The Journal of Finance, 40(3), 793-805. 
Fama, E.F., French, K.R. (2008). Dissecting Anomalies. The Journal of Finance, 63(4), 1653-1678.

Fama, E.F., French, K.R. (1998). Value versus Growth: The International Evidence.

The Journal of Finance, 53(6), 1975-1999.

Fama, E.F., French, K.R. (2012). Size, Value, and Momentum in International Stock Returns. Journal of Financial Economics, 105(3), 457-472.

Fama, E.F., French, K.R. (1993). Common Risk Factors in the Returns on Stocks and Bonds. Journal of Financial Economics, 33(1), 3-56.

Fama, E.F., French, K.R. (1992). The Cross-section of Expected Stock Returns. The Journal of Finance, 47(2), 427-466.

Grinblatt, M., Moskowitz, T.J. (2004). Predicting Stock Price Movements from Past Returns: The Role of Consistency and Tax-Loss Selling. Journal of Financial Economics, 71(3), 541-579.

Heston, S.L., Rouwenhorst, K.G., Weessels, R.E. (1999). The Role of Beta and Size in the Cross-section of European Stock Returns. European Financial Management, 5(1), 9 -27.

Horowitz, J.L., Loughran, T., Savin, N.E. (2000). The Disappearing Size Effect. Research in Economics, 54(1), 83-100.

Jegadeesh, N., Titman, S. (1993). Returns to Buying Winners and Selling Losers: Implications for Stock Market Efficiency. Journal of Finance, 48(1), 65-91.

Jegadeesh, N., Titman, S. (2001). Profitability of Momentum Strategies: An Evaluation of Alternative Explanations. Journal of Finance, 56(2), 699-720.

Kowerski, M. (2008). The Fama and French Tree-factor Model for Warsaw Stock Exchange (Trójczynnikowy model Famy i Frencha dla Giełdy Papierów Wartościowych w Warszawie). Przeglq̨d Statystyczny, 55(4), 131-148.

Liew, J., Vassalou, M. (2000). Can Book-to-Market, Size and Momentum Be Risk Factors that Predict Economic Growth? Journal of Financial Economics, 57(2), 221-245.

Lischewski, J., Voronkova, S. (2010). Size, Value and Liquidity. Do They Really Matter on an Emerging Stock Market? ZEW Discussion Paper, 10-070.

Reinganum, M.R. (1981). Misspecification of Capital Asset Pricing: Empirical Anomalies Based on Earning' Yield and Market Values. Journal of Financial Economics, 9(1), 19-46.

Rosenberg, B., Reid, K., Lanstein, R. (1985). Persuasive Evidence of Market Inefficiency. Journal of Portfolio Management, 11(3), 9-17.

Rouwenhorst, K.G. (1999). Local Returns Factors and Turnover in Emerging Stock Markets.

The Journal of Finance, 54(4), 1439 - 1464.

Stattman, D. (1980). Book Values and Stock Returns. The Chicago MBA: A Journal of Selected Papers, 4, $25-45$.

Zaremba, A., Konieczka, P. (2015). Are Value, Size and Momentum Premiums in CEE Emerging Markets Only Illusionary? Finance a úvěr-Czech Journal of Economics and Finance, 65(1), 84-104.

Zaremba, A. (2015a). Value, Size, Momentum, and Unique Role of Microcaps in CEE Market Stock Returns. Eastern European Economics, 53(3), 221-241.

Zaremba, A. (2015b). Country Selection Strategies Based on Value, Size, and Momentum. Investment Analyst Journal, 44(3), 171-198.

Zaremba, A. (2014). Cross-Sectional Asset Pricing Models for the Polish Market. Working paper, http://ssrn.com/abstract=2396884 or http://dx.doi.org/10.2139/ssrn.2396884. 


\section{Appendix: Tables}

Table 1: Pre-cost factor-sorted portfolios

\begin{tabular}{|c|c|c|c|c|c|c|c|c|c|c|c|c|}
\hline & \multicolumn{4}{|c|}{ Equal-weighted portfolios } & \multicolumn{4}{|c|}{ Capitalization-weighted portfolios } & \multicolumn{4}{|c|}{ Li quidity-weighted portfolios } \\
\hline & Return & Volatility & Beta & Volume & Return & Volatility & Beta & Volume & Return & Volatility & Beta & Volume \\
\hline \multicolumn{13}{|c|}{ Value portfolios } \\
\hline Low $30 \%$ & $13,1 \%$ & $46,0 \%$ & 1,09 & 2846 & $10,9 \%$ & $22,6 \%$ & 0,95 & 31190 & $6,5 \%$ & $30,4 \%$ & 0,89 & 40211 \\
\hline Mid 40\% & $21,2 \%$ & $43,4 \%$ & 0,95 & 2091 & $12,4 \%$ & $26,8 \%$ & 1,08 & 19945 & $16,0 \%$ & $34,4 \%$ & 1,11 & 31896 \\
\hline High $30 \%$ & $20,5 \%$ & $43,0 \%$ & 0,98 & 990 & $15,3 \%$ & $24,1 \%$ & 1,01 & 10508 & $4,5 \%$ & $21,6 \%$ & 0,57 & 14906 \\
\hline Market & $19,0 \%$ & $43,4 \%$ & 1,00 & 1980 & $12,4 \%$ & $22,8 \%$ & 1,00 & 25384 & $12,1 \%$ & $28,3 \%$ & 1,00 & 38192 \\
\hline \multicolumn{13}{|c|}{ Size portfolios } \\
\hline Low $30 \%$ & $24,1 \%$ & $50,1 \%$ & 1,28 & 190 & $21,2 \%$ & $50,1 \%$ & 1,93 & 194 & $4,9 \%$ & $68,0 \%$ & 1,69 & 1356 \\
\hline Mid 40\% & $18,2 \%$ & $51,1 \%$ & 1,19 & 467 & $16,6 \%$ & $43,5 \%$ & 1,56 & 568 & $8,0 \%$ & $56,6 \%$ & 1,47 & 1930 \\
\hline High $30 \%$ & $11,1 \%$ & $29,1 \%$ & 0,49 & 5723 & $12,1 \%$ & $22,1 \%$ & 0,97 & 26805 & $14,1 \%$ & $24,5 \%$ & 0,87 & 41551 \\
\hline Market & $19,0 \%$ & $43,4 \%$ & 1,00 & 1980 & $12,4 \%$ & $22,8 \%$ & 1,00 & 25384 & $12,1 \%$ & $28,3 \%$ & 1,00 & 38192 \\
\hline \multicolumn{13}{|c|}{ Momentum portfolios } \\
\hline Low $30 \%$ & $10,8 \%$ & $36,9 \%$ & 0,73 & 1400 & $13,2 \%$ & $29,4 \%$ & 1,08 & 10591 & $5,7 \%$ & $37,4 \%$ & 1,13 & 15671 \\
\hline Mid $40 \%$ & $17,8 \%$ & $44,7 \%$ & 1,09 & 1733 & $16,1 \%$ & $26,1 \%$ & 1,14 & 17155 & $15,0 \%$ & $31,7 \%$ & 0,91 & 26039 \\
\hline High $30 \%$ & $26,8 \%$ & $50,3 \%$ & 1,15 & 2886 & $9,7 \%$ & $27,1 \%$ & 0,91 & 27020 & $11,2 \%$ & $38,5 \%$ & 1,08 & 38155 \\
\hline Market & $19,0 \%$ & $43,4 \%$ & 1,00 & 1980 & $12,4 \%$ & $22,8 \%$ & 1,00 & 25384 & $12,1 \%$ & $28,3 \%$ & 1,00 & 38192 \\
\hline
\end{tabular}

Table 1 presents the pre-cost return characteristics offactor portfolios. Portfolios are sorted according to B/M ("value"), company capitalization ("size") or the total price change in the year preceding the portfolio formation ("momentum"). "Return" is the average annual geometric rate of return, "volatility" is the annual standard deviation of log-returns, "beta" is regression coefficient calculated against a defined market portfolio and "volume" is the cross-sectional weighted-average of single stocks' time-series averaged daily trading volumes in the month preceding the portfolio formation multiplied by the stock price.

Table 2: Pre-cost long/short factor mimicking portfolios

\begin{tabular}{lrrrrrrrrrr}
\hline & \multicolumn{3}{c}{ Value L/S portfolios } & \multicolumn{3}{c}{ Size L/S portfolios } & \multicolumn{3}{c}{ MomentumL/S portfolios } \\
& EW & CW & LW & EW & CW & LW & EW & CW & LW \\
\hline Return & $8,9 \%$ & $9,9 \% * *$ & $0,7 \%$ & $22,9 \% * *$ & $17,3 \%$ & $0,8 \%$ & $26,2 \% * *$ & $-3,9 \%$ & $5,5 \%$ \\
$t$-stat & 1,28 & 2,29 & 0,15 & 2,29 & 1,47 & 0,05 & 3,87 & $-0,38$ & 0,55 \\
Volatility & $24,2 \%$ & $14,9 \%$ & $16,2 \%$ & $34,6 \%$ & $40,8 \%$ & $53,4 \%$ & $23,5 \%$ & $35,4 \%$ & $34,6 \%$ \\
\hline & & & & CAPM model & & & & \\
b & $-0,14$ & 0,03 & $-0,34 * *$ & $0,59 * *$ & 0,72 & 0,70 & $0,41 * *$ & $-0,23$ & 0,02 \\
$t$-stat & $-0,83$ & 0,15 & $-2,55$ & 3,47 & 1,35 & 1,27 & 3,53 & $-0,48$ & 0,04 \\
$\alpha$ & $4,3 \%$ & $3,4 \%$ & $-3,2 \%$ & $8,0 \%$ & $5,9 \%$ & $-8,9 \%$ & $12,8 \% * *$ & $-8,3 \%$ & $-0,5 \%$ \\
$t$-stat & 0,61 & 0,73 & $-0,85$ & 1,07 & 0,50 & $-0,58$ & 2,56 & $-0,76$ & $-0,05$ \\
\hline
\end{tabular}

Table 2 presents pre-cost return characteristics of long/short factor mimicking portfolios. Portfolios are created based on B/M ("value"), company capitalization ("size") or the total price change in the year preceding the portfolio formation ("momentum"). "Return" is the average annual geometric rate of return and "volatility" is an annual standard deviation of log-returns. "EW", " $C W$ " and " $L W$ " denote equal-, capitalization- and liquidity-based weighting schemes. The liquidity-weighted portfolios were weighted according to the "volume" defined as stocks' time-series averaged daily trading volume in the month preceding the portfolio formation multiplied by the stock price. $\alpha$ and $\beta$ are model's parameters. ${ }^{*}$ and ${ }^{* *}$ indicate values significantly different from zero at $10 \%$ and $5 \%$ levels, respectively. 
Table 3: Factor correlations

\begin{tabular}{|c|c|c|c|c|c|}
\hline & Value L/S & Size $\mathrm{L} / \mathrm{S}$ & Momentum L/S & Market & Cash \\
\hline \multicolumn{6}{|c|}{ Equal-weighted portfolios } \\
\hline Value $\mathrm{L} / \mathrm{S}$ & 1,00 & & & & \\
\hline Size $\mathrm{L} / \mathrm{S}$ & $-0,41$ & 1,00 & & & \\
\hline MomentumL/S & $-0,44$ & 0,52 & 1,00 & & \\
\hline Market & $-0,25$ & 0,73 & 0,74 & 1,00 & \\
\hline Cash & 0,33 & $-0,15$ & $-0,10$ & $-0,11$ & 1,00 \\
\hline \multicolumn{6}{|c|}{ Ca pitalization-weighted portfolios } \\
\hline Value $\mathrm{L} / \mathrm{S}$ & 1,00 & & & & \\
\hline Size $\mathrm{L} / \mathrm{S}$ & 0,56 & 1,00 & & & \\
\hline MomentumL/S & $-0,47$ & $-0,55$ & 1,00 & & \\
\hline Market & 0,06 & 0,37 & $-0,14$ & 1,00 & \\
\hline Cash & 0,07 & $-0,28$ & 0,08 & 0,11 & 1,00 \\
\hline \multicolumn{6}{|c|}{ Li quidity-weighted portfolios } \\
\hline Value $\mathrm{L} / \mathrm{S}$ & 1,00 & & & & \\
\hline Size $\mathrm{L} / \mathrm{S}$ & 0,18 & 1,00 & & & \\
\hline MomentumL/S & $-0,12$ & $-0,55$ & 1,00 & & \\
\hline Market & $-0,61$ & 0,36 & 0,01 & 1,00 & \\
\hline Cash & 0,37 & $-0,17$ & 0,19 & $-0,14$ & 1,00 \\
\hline
\end{tabular}

Table 3 depicts Pearson's correlation coefficients of pre-cost log-returns among market neutral factor-mimicking portfolios, stock market portfolio ("market") and yields in the cash market ("cash"). Portfolios are created based on B/M ("value"), company capitalization ("size") or the total price change in the year preceding the portfolio formation ("momentum").

Table 4: Interactions between factors

\begin{tabular}{|c|c|c|c|c|c|c|c|c|c|}
\hline & \multicolumn{3}{|c|}{$\underline{\text { Return }}$} & \multicolumn{3}{|c|}{$\underline{\text { Volatility }}$} & \multicolumn{3}{|c|}{ Beta } \\
\hline \multicolumn{10}{|c|}{ Value and size portfolios } \\
\hline & $\begin{array}{c}\text { V: low } \\
30 \%\end{array}$ & $\begin{array}{c}\mathrm{V}: \mathrm{mid} \\
40 \%\end{array}$ & $\begin{array}{c}\text { V: high } \\
30 \%\end{array}$ & $\begin{array}{c}\text { V: low } \\
30 \%\end{array}$ & $\begin{array}{l}\mathrm{V}: \mathrm{mid} \\
40 \%\end{array}$ & $\begin{array}{c}\text { V: high } \\
30 \%\end{array}$ & $\begin{array}{c}\text { V: low } \\
30 \%\end{array}$ & $\begin{array}{c}\text { V: mid } \\
40 \%\end{array}$ & $\begin{array}{c}\text { V: high } \\
30 \%\end{array}$ \\
\hline S: low $30 \%$ & $28,1 \%$ & $26,9 \%$ & $21,9 \%$ & $67,5 \%$ & $53,9 \%$ & $45,9 \%$ & 1,01 & 0,91 & 0,76 \\
\hline S: $\operatorname{mid} 40 \%$ & $11,6 \%$ & $21,3 \%$ & $17,1 \%$ & $61,2 \%$ & $47,2 \%$ & $54,4 \%$ & 1,06 & 0,74 & 0,82 \\
\hline S: high $30 \%$ & $8,3 \%$ & $13,5 \%$ & $13,3 \%$ & $29,1 \%$ & $33,1 \%$ & $28,2 \%$ & 0,41 & 0,50 & 0,46 \\
\hline \multicolumn{10}{|c|}{ Value and momentum portfolios } \\
\hline & $\begin{array}{c}\text { V: low } \\
30 \%\end{array}$ & $\begin{array}{c}\text { V: mid } \\
40 \%\end{array}$ & $\begin{array}{c}\text { V: high } \\
30 \%\end{array}$ & $\begin{array}{c}\text { V: low } \\
30 \%\end{array}$ & $\begin{array}{c}\text { V: mid } \\
40 \%\end{array}$ & $\begin{array}{c}\text { V: high } \\
30 \%\end{array}$ & $\begin{array}{c}\text { V: low } \\
30 \%\end{array}$ & $\begin{array}{c}\text { V: mid } \\
40 \%\end{array}$ & $\begin{array}{c}\text { V: high } \\
30 \%\end{array}$ \\
\hline M: low 30\% & $-2,3 \%$ & $9,2 \%$ & $16,1 \%$ & $36,7 \%$ & $39,8 \%$ & $36,7 \%$ & 0,56 & 0,67 & 0,58 \\
\hline M: mid 40\% & $2,7 \%$ & $22,2 \%$ & $25,9 \%$ & $38,1 \%$ & $45,2 \%$ & $52,5 \%$ & 0,65 & 0,77 & 0,90 \\
\hline M: high 30\% & $24,7 \%$ & $25,9 \%$ & $30,9 \%$ & $56,2 \%$ & $48,0 \%$ & $58,2 \%$ & 0,91 & 0,71 & 0,84 \\
\hline \multicolumn{10}{|c|}{ Size and momentum portfolios } \\
\hline & $\begin{array}{c}\text { S: low } \\
30 \%\end{array}$ & $\begin{array}{c}\text { S: mid } \\
40 \%\end{array}$ & $\begin{array}{c}\text { S: high } \\
30 \%\end{array}$ & $\begin{array}{c}\text { S: low } \\
30 \%\end{array}$ & $\begin{array}{c}\text { S: mid } \\
40 \%\end{array}$ & $\begin{array}{c}\text { S: high } \\
30 \%\end{array}$ & $\begin{array}{c}\text { S: low } \\
30 \%\end{array}$ & $\begin{array}{c}\text { S: mid } \\
40 \%\end{array}$ & $\begin{array}{c}\text { S: high } \\
30 \%\end{array}$ \\
\hline M: low 30\% & $13,7 \%$ & $3,3 \%$ & $5,8 \%$ & $42,4 \%$ & $42,8 \%$ & $36,5 \%$ & 0,67 & 0,66 & 0,52 \\
\hline M: mid 40\% & $19,0 \%$ & $15,3 \%$ & $12,2 \%$ & $52,1 \%$ & $50,1 \%$ & $29,2 \%$ & 0,89 & 0,82 & 0,45 \\
\hline M: high 30\% & $39,1 \%$ & $29,6 \%$ & $6,7 \%$ & $68,9 \%$ & $61,1 \%$ & $32,1 \%$ & 1,08 & 1,05 & 0,44 \\
\hline
\end{tabular}

Table 4 presents pre-cost return characteristics of portfolios from double sorts. All portfolios are equal-weighted and created based on pairs of following variables: B/M ("value"), company capitalization ("size") or the total price change in the year preceding the portfolio formation ("momentum"). "Return" is the average annual geometric rate of return and "volatility" is an annual standard deviation of log-returns. 
Table 5: Long/short portfolios based on pairs of factors

\begin{tabular}{lrrr}
\hline & $\mathrm{V}+\mathrm{S}$ & $\mathrm{V}+\mathrm{M}$ & $\mathrm{S}+\mathrm{M}$ \\
\hline Return & $21,7 \% * *$ & $43,8 \% * *$ & $-0,8 \%$ \\
$t$-stat & 2,25 & 3,87 & $-0,04$ \\
Volatility & $33,5 \%$ & $39,2 \%$ & $78,2 \%$ \\
\hline \multicolumn{4}{c}{ CAPM model } \\
$\beta$ & $0,36 *$ & $0,46 * *$ & $-0,39$ \\
$t$-stat & 1,83 & 2,09 & $-0,71$ \\
$\alpha$ & $13,76 \%$ & $31,11 \%$ & $-8,60 \%$ \\
$t$-stat & 1,49 & 3,02 & $-0,33$ \\
\hline
\end{tabular}

Table5 presents pre-cost return characteristics of portfolios from double sorts. All portfolios are equal-weighted and created based on pairs of following variables: B/M ("V"), company capitalization ("S") or the total price change in the year preceding the portfolio formation ("M"). * and ** indicate values significantly different from zero at $10 \%$ and $5 \%$ levels, respectively.

Table 6: Bid-ask spreads

\begin{tabular}{|c|c|c|c|c|c|c|c|c|c|}
\hline & \multicolumn{3}{|c|}{ Value portfolios } & \multicolumn{3}{|c|}{ Size portfolios } & \multicolumn{3}{|c|}{ Momentum } \\
\hline & EW & CW & LW & EW & CW & LW & EW & CW & LW \\
\hline Low $30 \%$ & $2,74 \%$ & $0,83 \%$ & $0,55 \%$ & $4,70 \%$ & $3,76 \%$ & $2,56 \%$ & $3,54 \%$ & $1,53 \%$ & $1,05 \%$ \\
\hline Mid 40\% & $2,43 \%$ & $0,83 \%$ & $0,50 \%$ & $2,36 \%$ & $2,23 \%$ & $1,28 \%$ & $2,57 \%$ & $0,78 \%$ & $0,48 \%$ \\
\hline High $30 \%$ & $3,04 \%$ & $0,87 \%$ & $0,85 \%$ & $1,24 \%$ & $0,71 \%$ & $0,45 \%$ & $2,10 \%$ & $0,86 \%$ & $0,65 \%$ \\
\hline Market & $2,71 \%$ & $0,80 \%$ & $0,52 \%$ & $2,71 \%$ & $0,80 \%$ & $0,52 \%$ & $2,71 \%$ & $0,80 \%$ & $0,52 \%$ \\
\hline
\end{tabular}

The table 6. presents average bid-ask spreads for factor and market portfolios. The spreads are computed as $\left(P_{\text {ask }}-P_{\text {bid }}\right) / P_{\text {mid" }}$ where $P_{\text {ask }} P_{\text {bid" }} P_{\text {middenote }}$ consecutively the best available offer, the best available offer bid and the mid-prices at the time of portfolio formation. Portfolios are created based on B/M ("value"), company capitalization ("size") or the total price change in the year preceding the portfolio formation ("momentum"). "EW", "CW" and " $L W$ " denote equal-, capitalization- and liquidity-based weighting schemes. 
Table 7: Post-cost portfolios from single sorts

\begin{tabular}{|c|c|c|c|c|c|c|c|c|c|c|c|c|}
\hline & \multicolumn{4}{|c|}{ Equal-weighted portfolios } & \multicolumn{4}{|c|}{ Capitalization-weighted portfolios } & \multicolumn{4}{|c|}{ Li quidity-weighted portfolios } \\
\hline & Return & Volatility & Beta & Volume & Return & Volatility & Beta & Volume & Return & Volatility & Beta & Volume \\
\hline \multicolumn{13}{|c|}{ Value portfolios } \\
\hline Low $30 \%$ & $10,0 \%$ & $47,2 \%$ & 1,09 & 2846 & $10,0 \%$ & $22,8 \%$ & 0,95 & 31190 & $5,9 \%$ & $30,7 \%$ & 0,90 & 40211 \\
\hline Mid $40 \%$ & $18,6 \%$ & $44,2 \%$ & 0,94 & 2091 & $11,6 \%$ & $27,0 \%$ & 1,08 & 19945 & $15,5 \%$ & $34,5 \%$ & 1,11 & 31896 \\
\hline High & $17,3 \%$ & $\%$ & 0,98 & 990 & & & 1,01 & 10508 & $3,6 \%$ & $21,8 \%$ & 0,57 & 14906 \\
\hline Mar & $16,0 \%$ & $3 \%$ & 1,00 & 1980 & $6 \%$ & $23,0 \%$ & 1,00 & 25384 & $11,6 \%$ & $28,5 \%$ & 1,00 & 38192 \\
\hline \multicolumn{13}{|c|}{ Size portfolios } \\
\hline Low $30 \%$ & $18,5 \%$ & $52,5 \%$ & 1,29 & 190 & $16,8 \%$ & $52,0 \%$ & 1,95 & 194 & $1,5 \%$ & $70,0 \%$ & 1,69 & 1356 \\
\hline Mid $40 \%$ & $15,6 \%$ & $52,0 \%$ & 1,18 & 467 & $14,2 \%$ & $44,3 \%$ & 1,56 & 568 & $6,6 \%$ & $57,0 \%$ & 1,48 & 1930 \\
\hline High $30 \%$ & $9,9 \%$ & & 0,48 & 723 & $11,4 \%$ & & 0,97 & & $13,6 \%$ & $6 \%$ & 0,87 & 41551 \\
\hline & $16,0 \%$ & $4,3 \%$ & 1,00 & 1980 & $11,6 \%$ & $23,0 \%$ & 1,00 & 25384 & $11,6 \%$ &, $5 \%$ & 1,00 & 38192 \\
\hline \multicolumn{13}{|c|}{ Momentum portfolios } \\
\hline & $6,9 \%$ & ,2\% & 0,74 & 400 & $11,7 \%$ & $29,8 \%$ & 1,07 & 91 & $4,5 \%$ & $8,1 \%$ & 1,13 & 15671 \\
\hline Mid $40 \%$ & $15,0 \%$ & $45,5 \%$ & 1,08 & 1733 & $15,3 \%$ & $26,3 \%$ & 1,14 & 17155 & $14,5 \%$ & $31,9 \%$ & 0,91 & 26039 \\
\hline High 30\% & $24,4 \%$ & $51,1 \%$ & 1,15 & 2886 & $8,7 \%$ & $27,5 \%$ & 0,91 & 27020 & $10,5 \%$ & $38,8 \%$ & 1,08 & 38155 \\
\hline Market & $16,0 \%$ & $44,3 \%$ & 1,00 & 1980 & $11,6 \%$ & $23,0 \%$ & 1,00 & 25384 & $11,6 \%$ & $28,5 \%$ & 1,00 & 38192 \\
\hline
\end{tabular}

The table 7. presents the post-cost return characteristics of factor portfolios. Portfolios are sorted according to B/M ("value"), company capitalization ("size") or the total price change in the year preceding the portfolio formation ("momentum"). "Return" is the average annual geometric rate of return, "volatility" is an annual standard deviation of log-returns, "beta" is regression coefficient calculated against a defined market portfolio and "volume" is cross-sectional weighted-average of single stocks' time-series averaged daily trading volumes in the month preceding the portfolio formation multiplied by the stock price. ${ }^{*}$ and ${ }^{* *}$ indicate values significantly different from zero at $10 \%$ and $5 \%$ levels, respectively.

Table 8: Post-cost long/short factor mimicking portfolios

\begin{tabular}{|c|c|c|c|c|c|c|c|c|c|}
\hline & \multicolumn{3}{|c|}{ Value L/S portfolios } & \multicolumn{3}{|c|}{ Size L/S portfolios } & \multicolumn{3}{|c|}{ MomentumL/S portfolios } \\
\hline & EW & $\mathrm{CW}$ & LW & EW & $\mathrm{CW}$ & LW & EW & $\mathrm{CW}$ & LW \\
\hline Return & $3,1 \%$ & $8,1 \% *$ & $-0,8 \%$ & $15,2 \%$ & $11,9 \%$ & $-3,3 \%$ & $20,5 \% * *$ & $-6,3 \%$ & $3,8 \%$ \\
\hline t-stat & 0,43 & 1,82 & $-0,16$ & 1,31 & 0,94 & $-0,20$ & 2,90 & $-0,61$ & 0,38 \\
\hline Volatility & $24,8 \%$ & $15,4 \%$ & $16,7 \%$ & $40,3 \%$ & $43,8 \%$ & $56,5 \%$ & $24,5 \%$ & $36,0 \%$ & $34,8 \%$ \\
\hline \multicolumn{10}{|c|}{ CAPM model } \\
\hline$\beta$ & $-0,13$ & 0,04 & $-0,35 * *$ & $0,63 * *$ & 0,72 & 0,69 & $0,41 * *$ & $-0,25$ & 0,01 \\
\hline t-stat & $-0,75$ & 0,17 & $-2,53$ & 3,00 & 1,26 & 1,18 & 3,54 & $-0,51$ & 0,03 \\
\hline$\alpha$ & $-1,6 \%$ & $1,8 \%$ & $-4,8 \%$ & $2,7 \%$ & $1,8 \%$ & $-12,8 \%$ & $9,1 \% *$ & $-11,0 \%$ & $-2,1 \%$ \\
\hline$t$-stat & $-0,22$ & 0,38 & $-1,24$ & 0,30 & 0,14 & $-0,78$ & 1,78 & $-1,00$ & $-0,20$ \\
\hline
\end{tabular}

The table 8 presents post-cost return characteristics of long/short factor mimicking portfolios. Portfolios are created based on $B / M($ "value"), company capitalization ("size") or the total price change in the year preceding the portfolio formation ("momentum"). "Return" is the average annual geometric rate of return and "volatility" is an annual standard deviation of log-returns. "EW", "CW" and " $L W "$ denote equal-, capitalization- and liquidity-based weighting schemes. ${ }^{*}$ and ${ }^{* *}$ indicate values significantly different from zero at $10 \%$ and $5 \%$ levels, respectively. 